\title{
Elaboração e avaliação da qualidade de macarrão isento de glúten
}

\author{
Elaboration and quality evaluation of the gluten-free pasta
}

\author{
Letícia Tomicki ${ }^{I}$ Aline Andressa Rigo ${ }^{\mathrm{I}}$ Angelise Durigon ${ }^{\mathrm{I}}$ Luiz Carlos Gutkoski ${ }^{\mathrm{II}}$ \\ Jamile Zeni $^{I}$ Eunice Valduga ${ }^{I}$ Clarice Steffens ${ }^{I^{*}}$ Geciane Toniazzo $^{I}$
}

RESUMO

\begin{abstract}
Com a intenção de minimizar a carência de produtos isentos de glúten e tendo em vista o crescente aumento de celíacos, a elaboração de produtos diferenciais a base de farinha de arroz e milho torna-se uma alternativa de consumo e comercialização. Assim, este trabalho teve como objetivo avaliar os efeitos da adição de farinha de arroz e milho, e emulsificante nas características de qualidade (teste de cozimento, textura instrumental - firmeza e aceitabilidade) e fisico-químicas (proteinas, lipídios, carboidratos, minerais e fibra alimentar) de formulações de macarrão, mediante o emprego de metodologia de planejamento de experimentos, fixando a concentração de ovos in natura $(12 \%, \mathrm{~m} / \mathrm{m})$ e água $(20 \%, v / m)$. A formulação com $40 \mathrm{~g}$ de farinha de milho, $60 \mathrm{~g}$ de farinha de arroz e 0,4g de SSL por $100 \mathrm{~g}$ de farinha mista foi a que apresentou melhor resistência ao cozimento, menores perdas de sólidos na água de cocção $(2,12 \% \mathrm{~m} / \mathrm{m})$, textura $\left(30,40 \mathrm{~g} \mathrm{seg}^{-1}\right)$ e aceitabilidade superior a $85 \%$. Além disso, o uso de farinha de arroz, associado à farinha de milho, proporciona fonte de minerais (152mg de K, 1,55mg de Fe, 46mg de Mg, 20mg de Ca por 100g), proteinas $(\sim 7 \%)$, carboidratos $(52 \%)$ e fibras $(\sim 1 \%)$, importante suprimento nutricional para celíacos, por estes apresentarem perdas significativas destes nutrientes, devido à diarreia e à absorção restrita, característica da doença.
\end{abstract}

Palavras-chave: arroz, milho, massa, celíacos.

\section{ABSTRACT}

In order to minimize the deficiency of products with gluten-free and the growing number of celiac the elaboration of differential products using rice and maize flour becomes an alternative of consuming and marketing. This study aimed to evaluate the effects of rice and maize flour, and emulsifier addition in the quality characteristics (cooking test, instrumental texturefirmness and acceptability) and physic-chemical (proteins, lipids, carbohydrates, minerals and dietary fiber) of pasta formulation, by the use of experimental design methodology, fixing the concentration of in nature eggs $(12 \%, w / w)$ and water $(20 \%, v / w)$. The formulation with $40 \mathrm{~g}$ of maize flour, $60 \mathrm{~g}$ of rice flour and $0.4 \mathrm{~g}$ per $100 \mathrm{~g}$ of SSL mixed flour showed the better cooking resistance, reduced loss of solids in the cooking water $(2.12 \% \mathrm{~m} / \mathrm{m})$, texture (30.40 $\left.\mathrm{g} \mathrm{sec}^{-1}\right)$ and acceptability higher than 85\%. Furthermore, the use of rice flour associated with maize flour provide a source of minerals (152mg of $\mathrm{K}, 1.55 \mathrm{mg}$ of $\mathrm{Fe}, 46 \mathrm{mg}$ of $\mathrm{Mg}, 20 \mathrm{mg} \mathrm{Ca}$ per $100 \mathrm{~g})$, proteins ( 7\%), carbohydrates (52\%), fibers $(\sim 1 \%)$ important nutritional supplement for celiac, because they present significant losses of these nutrients due to restricted absortion and diarrhea, characteristic of the disease.

Key words: rice, maize, pasta, celiac.

\section{INTRODUÇÃO}

Os avanços tecnológicos vêm proporcionando o desenvolvimento de alimentos diferenciais, como os isentos de glúten (KOHMANN, 2010). No entanto, esses produtos, geralmente, são elaborados com farinhas e amidos refinados e, por isso, apresentam baixo teor de fibra alimentar, vitaminas e minerais, sendo alguns dos fatores responsáveis pelo consumo inadequado destes nutrientes pelos celíacos (THOMPSON et al., 2005). Diante disso, o desenvolvimento de novos produtos por meio da utilização de matérias-primas com valor nutricional agregado é fundamental para melhorar o aspecto nutricional da alimentação.

A presença do glúten é fator determinante para a qualidade de massas, pois agrega características como: extensibilidade e

'Departamento de Engenharia de Alimentos, Universidade Regional e Integrada do Alto Uruguai e das Missões (URI), 99700-000, Erechim, RS, Brasil. E-mail: claristeffens@yahoo.com.br. *Autor para correspondência.

${ }^{\mathrm{II}}$ Centro em Pesquisa em Alimentação (CEPA), Universidade de Passo Fundo (UPF), Passo Fundo, RS, Brasil. 
resistência ao alongamento à massa. A remoção do glúten resulta em grandes problemas na elaboração de massas, além de textura e sabor desagradáveis (GALLAGHER et al., 2004).

Estudos comprovam que massas alimentícias, não convencionais de boa qualidade, podem ser obtidas a partir da utilização de tecnologias que explorem as propriedades funcionais (tecnológicas) de componentes da matéria-prima, como o amido, ou adicionar farinhas ricas em proteínas, que são capazes de formar estrutura semelhante à do glúten (ORMENESE \& CHANG, 2002). Nesse sentido, a combinação de arroz (incluindo arroz integral) e o milho podem ser indicados na elaboração de macarrões isentos de glúten para portadores de enteropatia (doença celíaca).

$\mathrm{O}$ arroz é dentre os cereais cultivados o que mais se destaca, por ser alimento básico da maioria da população (SILVA, 2007; WALTER et al., 2008). $\mathrm{O}$ arroz possui outra vantagem, que é o baixo índice glicêmico, e ser rico em ácido glutâmico e aspártico (FERNANDES et al., 2000). Já o milho apresenta elevados teores de carboidratos e apresenta pigmentos criptoxantina e zeaxantina que além de serem precursores da vitamina A, atuam como corantes naturais, promovendo pigmentação sensorialmente atraente às massas (BERARDOA et al., 2004).

A fim de garantir qualidade nutricional e funcional, o objetivo deste trabalho foi avaliar os efeitos da adição de farinha de arroz, farinha de milho e emulsificante nas características de qualidade e físico-químicas de formulações de macarrão isento de glúten, mediante o emprego de metodologia de planejamento de experimentos.

\section{MATERIAL E MÉTODOS}

Elaboração de formulações de massa alimentícia tipo macarrão

Foram realizados testes preliminares a fim de definir as proporções das matérias-primas, insumos e/ou parâmetros de processo a serem utilizados na elaboração de massas alimentícias - Tipo Macarrão - isento de glúten. Para tal, variou-se a proporção farinha de arroz - Cerellus/Ijuí - RS (60:40, m/m) e milho - Cotrel/Erechim - RS (86,8:13,2m/m), emulsificantes Estearoil-2-Lactil Lactato de Sódio (SGS-SSL) - Granotec/Curitiba - PR (0,2 a 0,4\%, $\mathrm{m} / \mathrm{m}$ ) e Monoglicerideo Destilado (SGS-Mono 90M) - Granotec/Curitiba - PR (0,5 a 1\%, m/m). Fixando a concentração de ovos in natura - Naturovos/Salvador do Sul - RS $(12 \%, \mathrm{~m} / \mathrm{m})$ e água potável $(20 \%, \mathrm{v} / \mathrm{m})$, totalizando 5 ensaios em triplicata.
As formulações das massas foram submetidas ao teste de qualidade de cozimento e determinações dos sólidos dissolvidos na água de cocção. Sendo assim, foram definidos os níveis (proporções dos ingredientes) a serem utilizados em um planejamento fatorial completo $2^{2}$, totalizando 11 ensaios com triplicata do ponto central. As variáveis independentes foram a concentração de SGS-SSL $(0,118$ a $0,680 \mathrm{~g}$ por $100 \mathrm{~g})$ e proporção de farinha de arroz e milho $(31,8: 68,2$ a $88,8: 11,8 \mathrm{~g}$ por $100 \mathrm{~g})$ e as fixas, ovos in natura $(12 \mathrm{~g}$ por $100 \mathrm{~g})$ e água $(20 \mathrm{~mL}$ por $100 \mathrm{~g})$. As variáveis dependentes foram o teor de proteína, lipídios, carboidratos, umidade, cinzas, fibra bruta, componentes minerais ( $\mathrm{Ca}, \mathrm{Mg}, \mathrm{K}, \mathrm{Na}$ e $\mathrm{Fe}$ ), textura instrumental e teste de cozimento das formulações.

Os ingredientes foram adicionados em uma misturadora (G-Paniz) com capacidade de $25 \mathrm{~kg}$, sendo a água incorporada gradualmente e a massa foi misturada a $2,0 \mathrm{cv}$ por $10 \mathrm{~min}$. Em seguida, a massa foi processada em máquina extrusora (Pastaia II), contendo rosca, com taxa de compressão $1: 1$ e trefila com 23 orifícios de $1 \mathrm{~mm}$ por $5 \mathrm{~mm}$, revestidos internamente com teflon. Posteriormente, os macarrões foram acondicionados em embalagem de filme de prolipropileno na quantidade de $250 \mathrm{~g}$. As amostras foram mantidas resfriadas a $4^{\circ} \mathrm{C}$ por $24 \mathrm{~h}$ para a realização dos testes de qualidade cozimento e aceitabilidade, por um período de no máximo de 5 dias para a realização das análises físico-químicas.

Caracterização físico-química das formulações

Para as análises físico-químicas, as amostras de massas frescas foram escolhidas aleatoriamente, desintegradas (Mastermix ARNO) e realizado quarteamento manual, subdividindo em amostras de análise e contraprova (mantidas congeladas).

As determinações de lipídeos (L), fibra alimentar (FA), conteúdo proteico $(\mathrm{P})$, minerais (M) e umidade (U) foram realizadas seguindo metodologia da AOAC (2005). Os carboidratos foram quantificados pelo método indireto (BRASIL, 2003), por diferença dos constituintes (U, M, P, FA e $\mathrm{L})$, e os resultados foram expressos em porcentagem $(\%, \mathrm{~m} / \mathrm{m})$. O valor calórico das formulações foi calculado multiplicando-se os valores em gramas de proteínas, lipídios e carboidratos por $4,9,4 \mathrm{kcal} \mathrm{g}^{-1}$, respectivamente (BRASIL, 2003).

Os componentes minerais foram determinados por espectrometria de absorção atômica em chama - FAAS (Varian Spectra AA-55), segundo metodologia descrita por AOAC (2005). 
Os cálculos dos teores dos minerais nas amostras foram baseados em uma curva de calibração obtida com as soluções padrão.

Análise da qualidade das massas alimentícias

Teste de cozimento - O tempo de cozimento foi determinado pela cocção de $10 \mathrm{~g}$ de amostra em 140mL de água destilada em ebulição, até atingir a qualidade visual adequada em consequência da gelatinização do amido em toda a seção da massa. Este ponto foi determinado pela compressão de amostras de produto cozido, a cada 30 s, entre duas lâminas de vidro até o desaparecimento do eixo central. A quantidade de sólidos perdidos na água de cozimento foi determinada pela evaporação de $20 \mathrm{~mL}$ de água de cozimento, obtida segundo AOAC (2005).

Textura instrumental - A textura das massas pré-cozidas (2min) foi realizada em um texturômetro TA-XT2 (Stable Micro Systems, Surrey, England), analisando-se a firmeza com o corpo de prova (probe) A/LKB-F, conforme método 66-50.01 da AACC (2010). Os parâmetros para firmeza foram: velocidade do pré-teste $\left(0,5 \mathrm{~mm} \mathrm{~s}^{-1}\right)$; velocidade do teste $\left(0,17 \mathrm{~mm} \mathrm{~s}^{-1}\right)$; velocidade do pós-teste $(10 \mathrm{~mm}$ $\left.\mathrm{s}^{-1}\right)$; distância $(4,5 \mathrm{~mm})$; trigger type (button, altura inicial de $5 \mathrm{~mm}$ ).

Aceitabilidade - Trinta provadores não treinados, de ambos os sexos, com idade mínima de 10 a 50 anos, realizaram o teste de aceitabilidade, onde foi utilizado um delineamento construído em Blocos Incompletos Equilibrados, completandose um Bloco a cada onze julgamentos, com uma repetição por formulação, totalizando 33 julgamentos para cada formulação. Cada provador recebeu três amostras diferentes dos macarrões elaborados, pré-cozidos por $2 \mathrm{~min}$, contendo aproximadamente $30 \mathrm{~g}$, distribuídos em recipientes codificados com três dígitos e acompanhados de um copo de água mineral a temperatura ambiente, a ser utilizados pelo provador antes e entre as degustações das amostras. $\mathrm{O}$ indivíduo expressou o grau de gostar ou desgostar do alimento, através do Teste de Escala Hedônica, estruturada de nove pontos: 9 - Gostei muitíssimo e 1 - Desgostei muitíssimo (FARIA, 2002).

Tratamento estatístico

Os resultados foram tratados estatisticamente segundo metodologia de planejamentos de experimentos, com auxílio do software Statistica, versão 8.0, em nível de significância de 90 e/ou 95\% de confiança.

\section{RESULTADOS E DISCUSSÃO}

Características físico-químicas de massa alimentícia Inicialmente, avaliando a qualidade das massas alimentícias, mediante teste de cozimento (teor de sólidos totais), verificou-se que a melhor formulação foi da mistura de farinha de arroz e farinha de milho (60:40) e $0,4 \mathrm{~g}$ de SSL por $100 \mathrm{~g}$ de farinha, com menor teor de sólidos totais $(1,10 \%)$ na água de cocção. A partir desses resultados, os níveis destas variáveis foram redefinidos e a tabela 1 apresenta a matriz do planejamento fatorial completo

Tabela 1 - Matriz do planejamento fatorial completo $2^{2}$ (valores codificados e reais) e resposta em lipídios (LP), fibra alimentar (FA), proteínas $(\mathrm{PT})$, minerais totais $(\mathrm{M})$, carboidratos $(\mathrm{CH})$, umidade $(\mathrm{U})$ e valor calórico total (VCT).

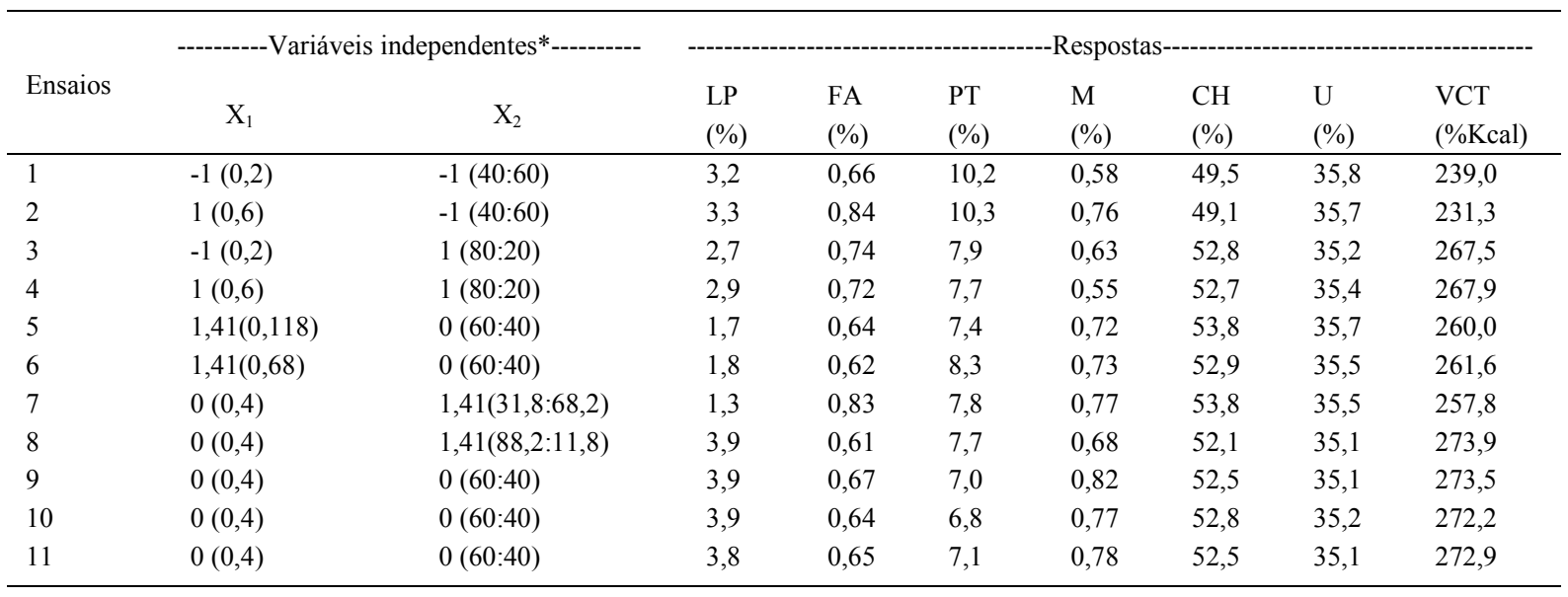

$* \mathrm{X}_{1}=$ Estearoil-2-Lactil Lactato de Sódio, SSL (g por $100 \mathrm{~g}$ de farinha), $\mathrm{X}_{2}=$ Farinha de Arroz: Farinha de Milho (g por 100g de farinha), LP = lipídios, $\mathrm{FA}=$ fibra alimentar, $\mathrm{PT}=$ proteína, $\mathrm{M}=$ mineral, $\mathrm{CH}=$ carboidratos, $\mathrm{U}=$ umidade e VCT $=$ valor calórico total. Variáveis independentes fixas: ovos e água. 
$2^{2}$ das formulações de macarrão isentas de glúten. Observou-se que os maiores teores de lipídios $(3,84 \%)$ encontram-se nos ensaios do ponto central. FERNANDES et al. (2013), ao avaliar o teor de lipídios em massas frescas, elaboradas a partir de farinha de arroz (100g) e albumina de ovo (10\%), verificaram baixos teores de lipídios $(0,12 \%)$.

Em relação à fibra alimentar (Tabela 1), os maiores teores foram verificados nos ensaios 2 e 7, que possuem concentrações superiores de farinha de milho, de 60 e $68,2 \mathrm{~g}$ por $100 \mathrm{~g}$ de farinha, respectivamente. Dessa forma, nenhuma das formulações de macarrão isento de glúten pode ser considerada fonte de fibra alimentar, pois, segundo a RDC no 54, de 12 de Novembro (BRASIL, 2012) é necessário um mínimo de 3\% para ser considerado um alimento "fonte de fibra".

Os teores de proteína foram encontrados em maiores quantidades $(\sim 10 \%)$ nos ensaios 1 e 2 (Tabela 1), os quais continham $60 \mathrm{~g}$ de farinha de milho por $100 \mathrm{~g}$ de farinha. Embora o percentual de proteína no grão de milho ser relativamente elevado (cerca de 10\%), possui baixa qualidade proteica, pois a zeína, que representa a maior fração das proteínas no grão (50 a $60 \%$ ), contém reduzidos teores de lisina e triptofano, enquanto que a fração glutelina (em menor proporção no grão) detém maior quantidade desses aminoácidos (OLIVEIRA et al., 2004). Sendo assim, confere um valor biológico de $50 \%$ à sua proteína, em relação a uma proteína de referência (NAVES et al., 2004).

Em relação aos teores de minerais totais (Tabela 1), há pouca variação entre as formulações, sendo que estes não foram influenciados significativamente $(\mathrm{P}<0,05)$ pelas proporções de farinha de arroz e/ou milho e de emulsificante utilizadas. Esses resultados corroboram os obtidos por FERNANDES et al. (2013), os quais obtiveram valor de $0,71 \% \mathrm{em}$ massas frescas elaboradas a partir de farinha de arroz $(100 \mathrm{~g})$ e albumina de ovo (10\%). Em relação aos carboidratos (Tabela 1), observa-se que há um menor teor $(\sim 49 \%)$ nas formulações 1 e 2 , que apresentam menor quantidade de farinha de arroz $(40 \mathrm{~g}$ por $100 \mathrm{~g}$ de farinha) na composição. O teor de umidade $(35,06$ a $35,81 \% \mathrm{~m} / \mathrm{m}$ ) não foi influenciado com a adição das farinhas de arroz e/ou milho e de SSL.

O valor calórico (Tabela 1) do macarrão isento de glúten (massa crua) apresentou maior teor de calorias (274kcal por $100 \mathrm{~g}$ ) no Ensaio 8 (88,2g de arroz por $100 \mathrm{~g}$ de farinha mista e $0,4 \mathrm{~g}$ de SSL por $100 \mathrm{~g}$ farinha mista).

A tabela 2 apresenta a matriz do planejamento fatorial completo $2^{2} \mathrm{e}$ as respostas para o teor de sódio, potássio, ferro, magnésio e cálcio das formulações de macarrão isento de glúten. Verifica-se que o ensaio 7 foi o que apresentou as maiores concentrações de $\mathrm{K}, \mathrm{Mg}$ e de $\mathrm{Fe}$, já o maior teor de $\mathrm{Na}$ encontra-se no ensaio 6 , e o maior teor de $\mathrm{Ca}$ encontra-se no ensaio 8, constituindo um fato positivo, pois o $\mathrm{Mg}$, assim como outros elementos competem pelo mesmo sítio ativo de absorção do $\mathrm{Ca}$, não sendo recomendada a ingestão em elevadas proporções em uma mesma refeição (MAHAN et al., 2005).

A equação 1 apresenta o modelo codificado de segunda ordem, que descreve o teor de ferro dos

Tabela 2 - Matriz do planejamento fatorial completo $2^{2}$ (valores codificados e reais) e resposta em teores de sódio, potássio, ferro, magnésio e cálcio das formulações de macarrão isento de glúten.

\begin{tabular}{|c|c|c|c|c|c|c|c|}
\hline \multirow{2}{*}{ Ensaio } & \multicolumn{2}{|c|}{----------Variáveis Independentes* } & \multicolumn{5}{|c|}{ 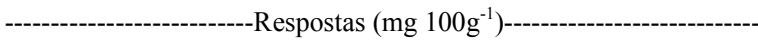 } \\
\hline & $\mathrm{X}_{1}$ & $\mathrm{X}_{2}$ & Sódio & Potássio & Ferro & Magnésio & Cálcio \\
\hline 1 & $-1(0,2)$ & $-1(40: 60)$ & 62,58 & 144,92 & 1,47 & 40,26 & 15,59 \\
\hline 2 & $1(0,6)$ & $-1(40: 60)$ & 91,50 & 150,16 & 1,50 & 41,35 & 16,81 \\
\hline 3 & $-1(0,2)$ & $1(80: 20)$ & 85,05 & 137,30 & 1,47 & 37,40 & 18,34 \\
\hline 4 & $1(0,6)$ & $1(80: 20)$ & 81,39 & 127,20 & 1,34 & 34,40 & 17,68 \\
\hline 5 & $-1,41(0,11)$ & $0(60: 40)$ & 90,05 & 160,21 & 1,50 & 42,36 & 19,71 \\
\hline 6 & $1,41(0,68)$ & $0(60: 40)$ & 92,68 & 159,63 & 1,46 & 41,91 & 18,68 \\
\hline 7 & $0(0,4)$ & $-1,41(31,8: 68,2)$ & 92,61 & 179,60 & 1,60 & 53,11 & 18,88 \\
\hline 8 & $0(0,4)$ & $1,41(88,2: 11,8)$ & 85,41 & 133,19 & 1,44 & 40,38 & 20,49 \\
\hline 9 & $0(0,4)$ & $0(60: 40)$ & 89,82 & 150,11 & 1,56 & 46,37 & 20,36 \\
\hline 10 & $0(0,4)$ & $0(60: 40)$ & 90,13 & 155,12 & 1,55 & 47,00 & 20,11 \\
\hline 11 & $0(0,4)$ & $0(60: 40)$ & 91,66 & 150,52 & 1,56 & 46,17 & 20,02 \\
\hline
\end{tabular}

$* \mathrm{X}_{1}=\mathrm{SSL}$ (g por $100 \mathrm{~g}$ de farinha), $\mathrm{X}_{2}=$ Farinha de Arroz: Farinha de Milho (g por $100 \mathrm{~g}$ de farinha). Variáveis independentes fixas: água filtrada, ovos, farinha de milho. 
macarrões em função das variáveis analisadas (farinha de arroz: farinha de milho e SSL). Todas as variáveis independentes apresentaram efeito significativo $(\mathrm{P}<0,05)$ para o teor de Fe. O modelo foi validado pela análise de variância, na qual se obteve um coeficiente de correlação de 0,87 e o F calculado de 1,40 vezes maior que o tabelado, os quais permitiram a construção da curva de contorno apresentada na figura 1.

$\mathrm{Fe}=1,56-0,018 .\left(\mathrm{X}_{1}\right)-0,054 .\left(\mathrm{X}_{1}\right)^{2}-0,047 .\left(\mathrm{X}_{2}\right)-$ 0,032. $\left(\mathrm{X}_{2}\right)^{2}-0,040 \cdot\left(\mathrm{X}_{1}\right) \cdot\left(\mathrm{X}_{2}\right)$

em que: $\mathrm{Fe}=$ Ferro $\left(\mathrm{mg} 100 \mathrm{~g}^{-1}\right), \mathrm{X}_{1}=\mathrm{SSL}(\mathrm{g}$ por $100 \mathrm{~g}$ de farinha) e $\mathrm{X}_{2}=$ Farinha de arroz: farinha de milho (g por $100 \mathrm{~g}$ de farinha).

A figura 1 demonstra que o aumento nos teores de ferro nos macarrões sem glúten é obtido quando as variáveis farinha de arroz: farinha milho e SSL forem adicionadas nas faixas próximas a $60: 40 \mathrm{~g}$ de farinha de arroz: farinha de milho e $0,4 \mathrm{~g}$ de SSL por $100 \mathrm{~g}$ de farinha, respectivamente. Dessa forma, o consumo de massa alimentícia - Tipo Macarrão - a base de farinha de arroz e milho, poderá suprir parte das necessidades de ferro por estes pacientes, sendo a anemia um dos sintomas causados pela doença celíaca (MAHAN et al., 2005).
A utilização de farinha de arroz e sua mistura com farinha de milho fornecem um bom aporte de minerais, pois a perda desses nutrientes é significativa, devido às diarreias e ao quadro de má absorção, característico da doença (REWERS, 2005). Além das farinhas, outras fontes alimentícias devem ser complementadas na dieta a fim de garantir o aporte completo diário destes minerais.

Análise da qualidade das massas alimentícias

A tabela 3 apresenta a matriz do planejamento fatorial completo $2^{2} \mathrm{e}$ as respostas para sólidos totais e textura instrumental (firmeza) das formulações de massas alimentícias pré-cozidas (2min) isentas de glúten. Observa-se que o menor teor de sólidos encontra-se nos ensaios 9, 10 e 11.

Em relação à textura (Tabela 3), observase que a maior firmeza $\left(33,68 \mathrm{~g} \mathrm{~s}^{-1}\right)$ encontra-se na formulação do Ensaio 4 (0,6g de SSL e proporção de $80 \mathrm{~g}$ de farinha de arroz: $20 \mathrm{~g}$ de farinha de milho por $100 \mathrm{~g}$ de farinha). A farinha de arroz favorece a polimerização com a fração de amido, criando uma estrutura que desempenha funções semelhantes ao

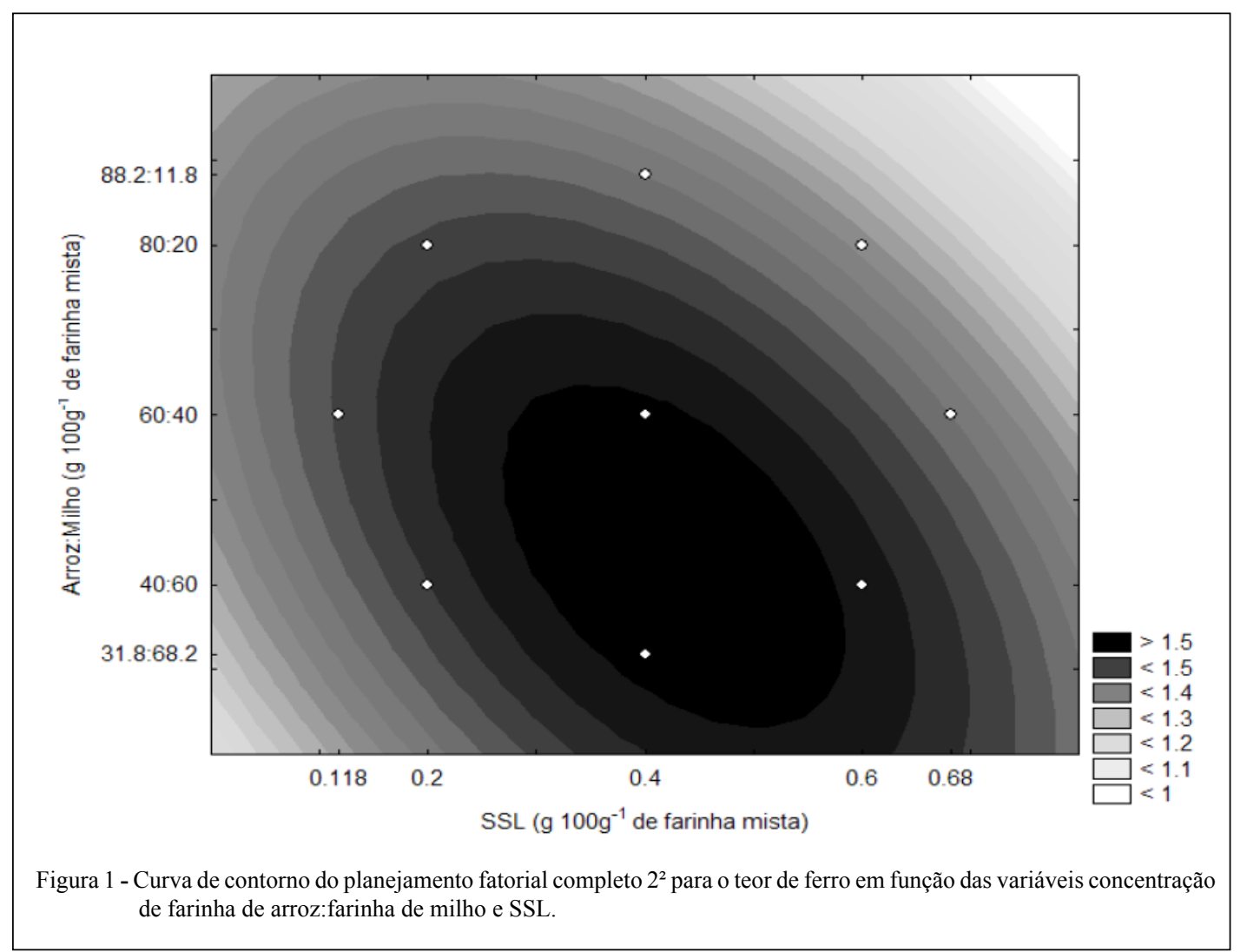

Ciência Rural, v.45, n.7, jul, 2015. 
Tabela 3 - Matriz do planejamento fatorial completo $2^{2}$ (valores codificados e reais) e resposta em sólidos totais, firmeza e aceitabilidade (AC) das formulações de macarrão isento de glúten.

\begin{tabular}{|c|c|c|c|c|c|}
\hline \multirow{2}{*}{ Ensaios } & \multicolumn{2}{|c|}{----------Variáveis independentes*---------- } & \multicolumn{2}{|c|}{ 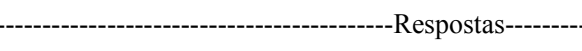 } & \multirow[b]{2}{*}{$\mathrm{AC}$} \\
\hline & $\mathrm{X}_{1}$ & $\mathrm{X}_{2}$ & Sólidos totais $\left({\left.\mathrm{g} 100 \mathrm{~g}^{-1}\right)}\right.$ & Firmeza $\left(\mathrm{g} \mathrm{seg}^{-1}\right)$ & \\
\hline 1 & $-1(0,2)$ & $-1(40: 60)$ & 2,72 & 30,98 & 6,90 \\
\hline 2 & $-1(0,6)$ & $-1(40: 60)$ & 2,22 & 32,70 & 6,50 \\
\hline 3 & $1(0,2)$ & $1(80: 20)$ & 4,9 & 31,36 & 7,23 \\
\hline 4 & $1(0,6)$ & $1(80: 20)$ & 5,31 & 33,68 & 7,20 \\
\hline 5 & $-1,41(0,118)$ & $0(60: 40)$ & 4,40 & 30,98 & 6,9 \\
\hline 6 & $1,41(0,68)$ & $0(60: 40)$ & 4,12 & 28,55 & 7,03 \\
\hline 7 & $0(0,4)$ & $-1,41(31,8: 68,2)$ & 3,40 & 30,98 & 7,27 \\
\hline 8 & $0(0,4)$ & $1,41(88,2: 11,8)$ & 5,44 & 33,49 & 7,17 \\
\hline 9 & $0(0,4$ & $0(60: 40)$ & 2,16 & 30,37 & 7,66 \\
\hline 10 & $0(0,4)$ & $0(60: 40)$ & 2,17 & 30,59 & 7,68 \\
\hline 11 & $0(0,4)$ & $0(60: 40)$ & 2,16 & 30,40 & 7,69 \\
\hline
\end{tabular}

$* \mathrm{X}_{1}=\mathrm{SSL}$ (g por $100 \mathrm{~g}$ de farinha), $\mathrm{X}_{2}=$ Farinha de Arroz: Farinha de Milho (g por $100 \mathrm{~g}$ de farinha) e AC= aceitabilidade. Variáveis independentes fixas: água filtrada, ovos, farinha de milho.

glúten na massa, evitando a aderência da massa após cozimento (FERNANDES et al., 2013).

Geralmente, materiais que contenham fibras e/ou uma quantidade relativamente alta de proteína, possuem maior perda de sólidos na água de cocção (CRUZ \& SOARES, 2004), porém uma explicação para a menor perda de sólidos deve-se ao fato da adição de emulsificantes à massa. No caso de massas alimentícias não convencionais, procurase formar uma estrutura semelhante a do glúten através do emprego de tecnologias que explorem as propriedades funcionais do amido presente na matériaprima ou através da adição de aditivos (ORMENESE \& CHANG, 2003), como é o caso da massa pré-cozida a base de farinha de arroz e milho, onde se empregou como aditivo coadjuvante os emulsificantes.

Outro fato é a formação de um complexo entre emulsificante e amilose, o qual resulta em mudanças no transporte de água para dentro dos grânulos de amido. Se esses complexos forem formados na superfície do grânulo de amido, um filme insolúvel poderá ser formado, resultando em um atraso na gelatinização durante a cocção (LAI, 2001). EDWARDS et al. (1993) avaliaram as características de firmeza de massas contendo grano duro, em diferentes tempos de cozimento. Eles encontraram resultados semelhantes às massas pré-cozidas de farinha de arroz e farinha de milho, com firmeza de $30,5 \mathrm{~g} \mathrm{~s}^{-1} \mathrm{em}$ amostras submetidas a $12 \mathrm{~min}$ de cozimento.

A equação 2 apresenta o modelo codificado de segunda ordem, que descreve a aceitabilidade das formulações dos macarrões em função das variáveis analisadas. Todas as variáveis independentes apresentaram efeito significativo $(\mathrm{P}<0,10)$ para a aceitabilidade. $\mathrm{O}$ modelo foi validado pela análise de variância, onde se obteve um coeficiente de correlação de 0,90 e o $\mathrm{F}$ calculado de 1,30 vezes maior que o valor tabelado, os quais permitiram a construção de curva de contorno apresentada na figura 2 .

$\mathrm{AC}=7,68$ - 0,031. $\left(\mathrm{X}_{1}\right)-0,391 .\left(\mathrm{X}_{1}\right)^{2}+0,111 .\left(\mathrm{X}_{2}\right)$ 0,263. $\left(\mathrm{X}_{2}\right)^{2}+0,092 \cdot\left(\mathrm{X}_{1}\right) \cdot\left(\mathrm{X}_{2}\right)$

em que: $\mathrm{AC}=$ Aceitabilidade, $\mathrm{X}_{1}=\mathrm{SSL}$ (g por $100 \mathrm{~g}$ de farinha) e $X_{2}=$ Farinha de arroz:farinha de milho (g por $100 \mathrm{~g}$ de farinha).

A figura 2 demonstra que a maior aceitabilidade $(7,68$ - gostei muito, $85 \%$ de aceitabilidade) das formulações de macarrão encontra-se em regiões próximas a $60: 40 \mathrm{~g}$ de farinha de arroz:farinha de milho e $0,4 \mathrm{~g}$ de SSL por $100 \mathrm{~g}$ de farinha, respectivamente.

\section{CONCLUSÃO}

Do ponto de vista nutricional, verificou-se que o uso de farinha de arroz na elaboração de massas alimentícias apresentou teor reduzido de carboidratos e maior percentual de proteína, magnésio, potássio e ferro, quando comparada à farinha de milho. Porém, a adição de farinha de milho às massas foi fundamental para a obtenção de qualidade tecnológica durante o cozimento, melhor resistência à quebra, além de uma coloração semelhante a massas contendo 


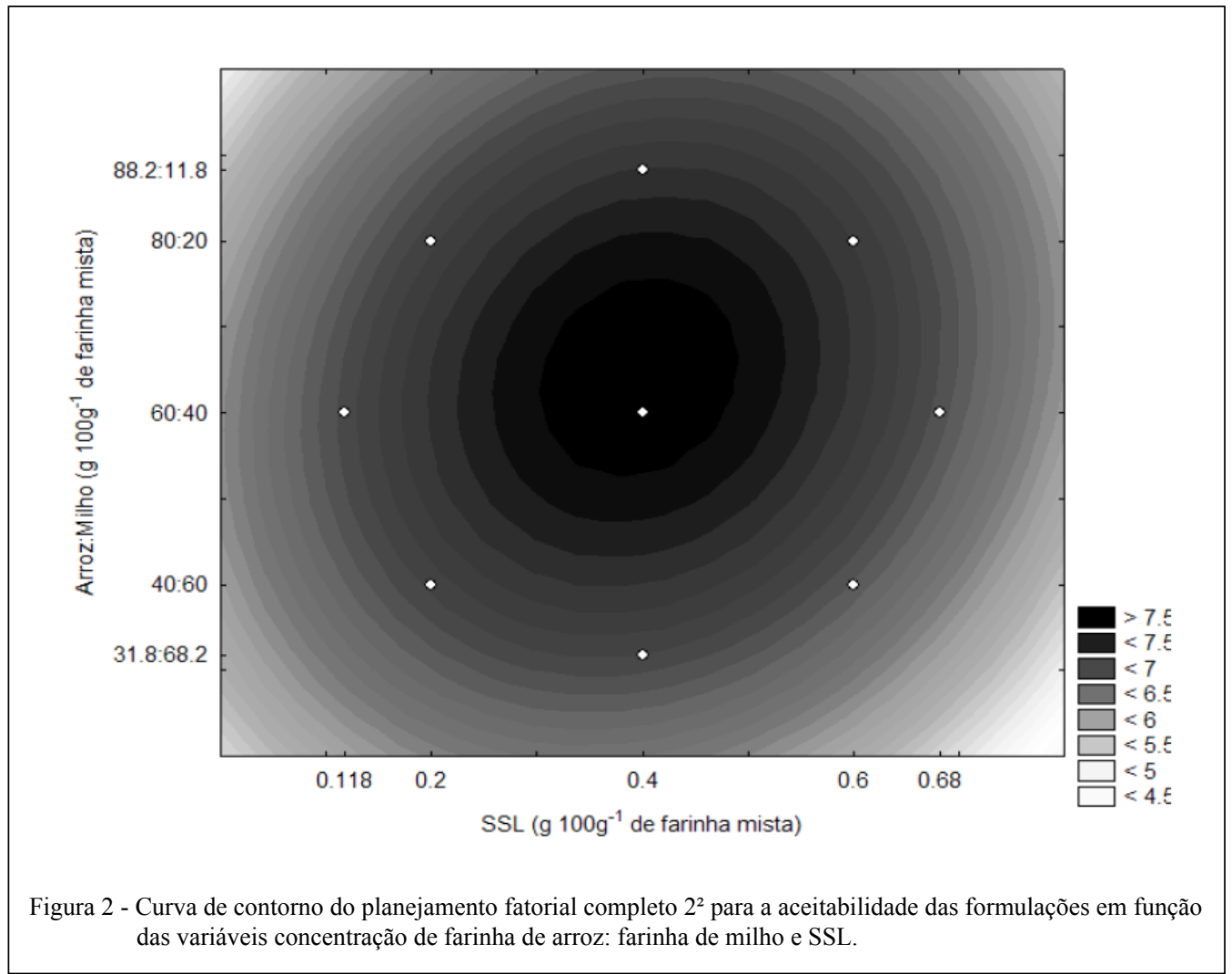

ovos, melhorando seu aspecto sensorial, em todos os quesitos avaliados. Assim, a formulação com $40 \mathrm{~g}$ de farinha de milho, $60 \mathrm{~g}$ de farinha de arroz e $0,4 \mathrm{~g}$ de SSL por $100 \mathrm{~g}$ de farinha mista foi a que apresentou melhor resistência ao cozimento, menores

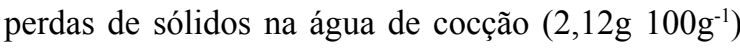
e firmeza adequada $\left(30,40 \mathrm{~g} \mathrm{~s}^{-1}\right)$, bem como aspectos sensorialmente aceitáveis (aceitabilidade superior a $85 \%$ ). Dessa forma, a produção de massas a base de farinha de arroz e milho com adição de emulsificante SSL (Estearoil-2-lactil lactato de sódio) constitui uma interessante alternativa, principalmente, para pacientes celíacos.

\section{AGRADECIMENTOS}

Os autores agradecem o apoio financeiro do Conselho Nacional de Desenvolvimento Científico e Tecnológico (CNPq), Fundação de Amparo à Pesquisa do Estado do Rio Grande do Sul (FAPERGS) e Coordenação de Aperfeiçoamento de Pessoal de Nível Superior (CAPES)

\section{REFERÊNCIAS}

AMERICAN ASSOCIATION OF CEREAL CHEMISTS (AACC). Approved methods of the AACC. 11.ed. St. Paul, 2010. 1200p.
ASSOCIATION OF OFFICIAL AGRICULTURAL CHEMISTS (AOAC). Official methods of analysis of the Association of Official Agriculture Chemists. Washington, 2005. 1141p.

BERARDOA, N. et al. Carotenoids concentration among maize genotypes measured by near infrared reflectance spectroscopy (NIRS). Innovative Food Science and Emerging, v.5, p.393398, 2004. Disponível em: <http://www.citeulike.org/user/ AldoRosales/article/10616824>. Acesso em: 20 nov. 2003. doi: 10.1016/j.ifset.2004.03.001.

BRASIL. Agência Nacional de Vigilância Sanitária. Resolução RDC n. 360 de 23 de dezembro de 2003. Regulamento técnico referente à Rotulagem Nutricional de Alimentos Embalados. Diário Oficial da União, Poder Executivo, de 26 de dezembro de 2003.

BRASIL. Ministério da Saúde. Secretaria de Vigilância Sanitária. RDC $n^{\circ} 54$ de 12 de Novembro de 2012. Regulamento Técnico sobre à Informação Nutricional Complementar. Diário Oficial da União, Poder Executivo, de 21 de agosto de 2006.

CRUZ, R.S.; SOARES, N.F.F. Efeito da adição de $\mathrm{CO}_{2}$ nas características tecnológica e sensorial do macarrão massa fresca tipo talharim. Ciência e Agrotecnologia, v.28, n.4, p.848-855, 2004. Disponível em: <http://www.scielo.br/scielo.php?pid=S141370542004000400017\&script=sci_arttext $>$. Acesso em: 12 jun. 2013. doi: 10.1590/S1413-70542004000400017.

EDWARDS, N.M. et al. Cooked pasta texture: comparision of dynamic viscoelastic properties. Journal of Food Science, 
v.70, p.122-126, 1993. Disponível em: <http://eurekamag.com/ research/008/388/008388353.php\#close>. Acesso em: 22 ago. 2013.

FARIA, E.V.; YOTSUYANAGI, K. Técnicas de análise sensorial Campinas: ITAL/LEFISE, 2002. 116p.

FERNANDES, M.S. et al. Effect of adding unconventional raw materials on the technological properties of rice fresh pasta. Food Science and Technology, v.33, n.2, p.257-264, 2013. Disponível em: <http://www.scielo.br/pdf/cta/v33n2/aop cta 5581.pdf $>$. Acesso em: 03 set. 2013. doi: 10.1590/S010120612013005000041

GALLAGHER, E. et al. Recent advances in the formulation of gluten-free cereal-based products. Trends in Food Science \& Technology, v.15, n.3-4, p.143-152, 2004.

KOHMANN, L.M. Desenvolvimento de pão branco e integral livres de glúten e fortificado com cálcio e ferro. 2010. $54 \mathrm{f}$. Monografia (Especialização em Engenharia de Alimentos) UFRGS, RS.

LAI, H.M. Effects of rice properties and emulsifiers on the quality of rice pasta. Journal of the Science of Food and Agriculture, v.82, p.203-216, 2001. Disponível em: <http://onlinelibrary. wiley.com/doi/10.1002/jsfa.1019/pdf>. Acesso em: 20 set. 2013. doi: $10.1002 /$ jsfa.1019.

MAHAN, L.K. et al. Alimentos, nutrição \& dietoterapia. 11.ed. São Paulo: Roca, 2005. 44p.

NAVES, M.M.V. et al. Avaliação química e biológica da proteína do grão em cultivares de milho de alta qualidade protéica. Pesquisa Agropecuária Tropical, v.34, n.1, p.1-8, 2004. Disponível em: $<\mathrm{http}$ ://www.revistas.ufg.br $>$. Acesso em: 10 nov. 2013. doi: 10.1590/S0101-20612006000300014.
OLIVEIRA, J.P. et al. Teor de proteína no grão em populações de milho De alta qualidade protéica e seus cruzamentos. Pesquisa Agropecuária Tropical, v.34, p.45-51, 2004. Disponível em: $<$ http://www.ufgd.edu.br/editora/cadernos-academicos/alimentose-alimentacao-animal>. Acesso em: 10 nov. 2013.

ORMENESE, R.C.; CHANG, Y.K. Macarrão de arroz: características de cozimento e textura em comparação com o macarrão convencional e aceitação pelo consumidor. Brazilian Journal of Food Technology, v.6, n.1, p.91-97, 2003. Disponível em: <http://www.ital.sp.gov.br/bj/artigos/brazilianjournal/free/ p03117.pdf>. Acesso em: 04 dez. 2013.

REWERS, M. Epidemiology of celiac disease: what are the prevalence, incidence, and progression of celiac disease? Gastroenterology, v.128, n.4, p.S47-S51, 2005. Disponível em: $<$ http://www.gastrojournal.org/article/S0016-5085(05)00199-X>. Acesso em: 05 dez. 2013. doi:10.1053/j.gastro.2005.02.030.

SILVA, E.M.M. Produção de macarrão pré-cozido à base de farinha mista de arroz integral e milho para celíacos utilizando o processo de extrusão. 2007. 118f. Dissertação (Mestrado em Ciência) - Instituto de Tecnologia, Universidade Rural do Rio de Janeiro, RJ.

THOMPSON, T. et al. Gluten-free survey: are the Americans with celiac disease consum ingre commended amounts of fibre, iron, calcium and grain foods? The British Dietetic Association. LTDA. Journal of Human Nutrition and Dietetics, v.18, p.163-169, 2005. Disponível em: <http://www.ncbi.nlm.nih.gov/ pubmed/15882378>. Acesso em: 17 jun. 2013.

WALTER, M. et al. Arroz: composição e características nutricionais. Ciência Rural, v.38, n.4, p.1184-1192, 2008. Disponível em: $<$ http://www.scielo.br/pdf/cr/v38n4/a49v38n4.pdf $>$. Acesso em: 12 set. 2013, doi: 10.1590/S0103-84782008000400049. 